\title{
Teaching Practice in the 21st Century: Emerging Trends, Challenges and Opportunities
}

\author{
Cecelia Jansen ${ }^{1, *}$, Petro van der Merwe ${ }^{2}$ \\ ${ }^{1}$ Department of Educational Leadership and Management, College of Education, Unisa \\ ${ }^{2}$ Department of Psychology, College of Human Sciences, Unisa
}

Copyright () 2015 Horizon Research Publishing All rights reserved.

\begin{abstract}
Digital technology for teaching practice students means the ability of student teachers to use digital artefacts as integral part of their pedagogical content knowledge. Student teachers need to be also aware of what implications this has for teaching and learning strategies plus the building aspects in the lesson presentation. A new approach to teaching practice, calibrated for the $21^{\text {st }}$ century, requires teachers to be willing to assist the student teachers in this regard. The teaching practice period is meant to expose student teachers to the most sobering technological frontier in history because they inherit a complex set of global dilemmas and this emphasise the rational of this study. The proposed study aims to prepare teaching practice students for the classrooms of the future. Teachers often expressed their lack of confidence in their digital technology skills and this can implicitly affect their attitudes towards the use of digital technology in their teaching. Therefore, the presenters argue that, the teaching practice student should be empowered in the fast-paced digital environment of the current millennium generation. Teachers often do not expect learners to be sharing knowledge through connections. This is a key aspect of learning in the digital age within a connectivist learning theory. The empirical research has been conducted in an interpretive qualitative paradigm underpinned by a complexity theory conceptual framework. Convenience sampling has been used in this study. One teacher from each of the three secondary schools in Gauteng has been selected to participate. This study has challenged the participating teachers to reflect on their own teaching praxis when using digital technology as an integrated part of their pedagogical content knowledge. One of the outputs of this research study is a model for teachers to use as an example for training the teaching practice students. This model can also be a source of information for digital technology literacy education. The intention is to guide teaching practice students to develop their own programmes for digital technology literacy to meet the teaching demands for the $21^{\text {st }}$ century.
\end{abstract}

Keywords Digital Technology Literacy Education, Teaching Practice, Millennium Generation, Digital Artefacts for Pedagogical Content Knowledge

\section{Digital Technology Literacy: A New Approach to Teaching Practice}

\section{Introduction}

The world children grow up in today is increasingly multimodal due to ever new technologies Okeke, Van Wyk \& Phasha [1] researchers argue that the these technologies shape what it means to be literate in the $21^{\text {st }}$ century as it continues to impact on how information is communicated and exchanged. This naturally determines the skills teaching practice students need - and raises the question whether the current pedagogy curriculum for teaching practice recognises these all-important skills. Marais and Meier [2] assert that the term teaching practice represents the range of experiences to which student teachers are exposed when they work in classrooms and schools. Therefore the relationship between classroom teachers (mentors) and teaching practice students are important Louw \& du Toit [3].

The researchers debate that classroom teachers have to give the teaching practice students' valuable advice and share their skills and experience. However, some teachers fear change, and so they hold on to traditional teaching Peterson [4]. Some teachers believe there is no urgent need for a change to a new educational model and they will even resist change at all cost Codrington \& Grant-Marshall [5]. Teachers might think they do not need to change, as they succeeded without the digital tools. This can cause a digital divide between teaching practice students and teachers. Teachers may not feel comfortable with the digital tools, which would create a gap between them and the teaching practice students who are more comfortable with digital tools. Godrington and Grant-Marshall [5 p 146] describe it as follows:

It has required a HUGE paradigm shift, which only the best teachers have succeeded in making successful.

Some teachers' use of technology is sometimes limited and they are not interested in social media tools. While teaching practice students know that technology is a part of today's world and thrive on technology and gadgets. 
Although, many teaching practice students may not feel an affinity for digital technologies and need constant guidance from classroom teachers, for example preparing a lesson in a way where technology can be integrated in a meaningful and functional way.

The researchers argue that the effective development of digital technology literacy in teaching practice training should be seen as a process of professional, inter-professional and curricular development as much as teacher training and development. Williams and Wavell [6] state that providing teachers with a model for the process of digital technology literacy teaching may not be as helpful as allowing them to discuss, collaborate and form consensus about the subject at teaching practice level.

One benefit of the model proposed in this article is that it acknowledges that sound digital technology learning entails revisiting a concept repeatedly over a period of time in order for teaching practice students to learn and fully understand the concept of digital artefacts as an integrated part of their pedagogical content knowledge. The curriculum should, according to the researchers, revisit basic ideas repeatedly and build on them, and therefore the teacher has to act as a facilitator to guide and navigate the teaching practice student through a process that enables the teaching practice student to use critical thinking in the context of new technology.

With the deictic changes in information, communication, and technology, the role of teachers is changing and becoming more important in a way that teachers have to think about teaching practice students who are eager about technology use Leu, Kinzer, Coiro, \& Cammak [7]. The main aim of this conceptual article is to explore the way teachers; mainly those who come from low technology areas can change their methodology and content to fit with the digital frame in teaching practice. The proposed model includes a dimension for teachers to once they understand the areas of changes, teachers will encourage teaching practice students to be more creative than they already are with regard to digital technology literacy teaching skills.

This study reminds us that digital technology literacy is multidimensional. The nature and extent of the digital technology literacy an individual needs and develops largely depend on the purposes they use new technology for in the first place. The researchers argue that different social groups may also require different forms of digital technology literacy, depending on their motivations for new technology use and therefore teachers need to guard against a reductive or mechanistic approach when assessing the levels of digital technology literacy in teaching practice students.

In relation to the teaching of new technology literacy, the researchers use the all-encompassing term 'digital media literacy'. A general definition of this term is that it incorporates the skills, knowledge, creativity and attitudes everyone needs when using digital media for learning and mastering the knowledge society Newman [8]. This is, however, a general definition, which only to a certain extent manages to encompass digital media literacy in school settings. Therefore, the researchers have found it necessary to include a narrower definition that more directly focuses on teaching practice teachers and digital media literacy in school settings: Digital media literacy for in-service teachers is the ability to use digital artefacts as an integrated part of their pedagogical content knowledge and be aware of what implications this has for teaching, learning strategies and building aspects. Almas \& Krumsvik [9 p 480].

Growing up in the digital age means that learners have an infinite amount of information available through the internet, but it also means learning reasonable and safe behaviour while online Levine and Cureton [10] have stated in the nineteenths [1998] that the digital media generation is no better and no worse than any other generation, but, like every other generation before, is unique. This generation is different, as their times are different Codrington \& Grant-Marshall [5]. Above all, today's learners are in need of a digital media literacy education that equips them with four crucial life skills: critical thinking, responsibility, an appreciation of differences, and efficacy. Rosen [11] argues about the fact that teachers' fear of change is not necessarily connected to digital tools only, but also that teachers are worried about the neurological, social, and psychological effects of learners' overuse and misuse (including abuse) of technology Okeke, Van Wyk, Phasha [1]. Consequently, this generation requires a unique brand of education that will enable them to realise their personal dreams and serve the society of which they form part.

Teachers cannot afford to ignore or trivialise the complex social, intellectual and emotional functions of digital technologies in the lives of young people Hobbs \& Frost [12]. In order to reach today's learners, teachers need to be responsive to learners' experience with their culture which is what they experience through television, movies, YouTube, the internet, Facebook, music and gaming. When teachers learn more about learners' choices, the first 'thing' they will notice is how different their learners are from them. When it comes to media and technology, every two years brings a new set of changes in the landscape of their daily life. Even if a teacher is only a few years older than his or her learners, there may be important differences because technology tools are changing so very rapidly. That is why teachers need to gain the latest information about the media and technology choices learners make at home (and at school) each day Ungar [13]. This situation highlights the need for orientation programmes in South African teaching practice training that adequately prepare teaching practice students for the complex and dynamic teaching situation of the $21^{\text {st }}$ century.

A study on digital media literacy around the world found that there are eight factors that appear to be crucial to the successful development of digital media literacy programmes in teacher training Pungente [14]. The eight factors are:

- Digital media literacy programmes, like other innovative programmes, must be a grassroots movement. Teachers need to take the initiative in lobbying for its inclusion in the curriculum. 
- Educational authorities must give clear support to such programmes by mandating the teaching of digital media studies within the curriculum, establishing guidelines and resource books, ensuring that curricula are developed, and making certain materials available.

- Faculties of education must hire staff capable of training future teachers in this area. There should also be academic support from tertiary institutions in the writing of curricula and in sustained consultation.

- In-service training at school district level must be an integral part of programme implementation.

- School districts need consultants who have expertise in digital media literacy and who will establish communication networks.

- Suitable textbooks and audiovisual material that are relevant to the country and/or area must be available.

- A support organisation must be established for the purposes of workshops, conferences, dissemination of newsletters, and developing curriculum units. Such a professional organisation must cut across school boards and districts to involve a cross-section of people interested in digital media literacy.

- There must be appropriate evaluation instruments suitable to the unique attributes of digital technology.

Because digital media literacy education involves such a diversity of skills and expertise, there must be collaboration between teachers (schools), tertiary institutions (researchers) and Department of Education.

\section{- Digital media literacy: a plan of action}

In this section, the theoretical and conceptual aspects of media literacy education are explored in order to find a framework for a model for digital media literacy education in teaching practice training. Ultimately, the goal of digital media literacy education should be to enable teaching practice students to develop their own creative as well as critical capacities in relation to the use of technology in the classroom. In doing so, the researchers argue that the teachers (including the teaching practice students) will realise that their choices are not limited to adjusting themselves to a century determined by technology; instead, they will have the awareness, the moral and ethical sensibilities, and the will to adjust technology to fit into their 21 st century teaching practices.

Today's learners engage in activities on interactive websites, TV programmes and other media and technologies that shape their literate identity Ungar [13]. Using technology in the classroom, teachers are becoming active participators and developers. Typical competencies have not been clarified by research at the time of this study, and this should be rectified in order to enable the development of appropriate curricula on pedagogy. The researchers argue that competence can no longer be restricted to individual competencies - it should also be defined in terms of collective intelligence. Teaching practice students need to use technology to share ideas, evaluate others and work collaboratively.

The researchers want to emphasise the fact that when digital media literacy merely entails the pursuit of skills to be able to use the latest technology, then the means becomes the end. Over and above the necessary skills, digital media literacy must include teacher's attitudes towards technology, as well as knowledge of the effects technology has on learners and society as a whole.

It is also important to note that the lack of software or digital tools does not prevent teachers from changing their practices. In developing countries, digital tools are not as sophisticated as the ones used in developed countries. However, teachers can adapt their teaching in spite of the little available tools. Several studies have been conducted on student teacher's experience and anxieties during teaching practice Ngidi \& Sibaya [18]; Marais \& Meier, 2004 [2] to mention but two.

However, a review of the literature indicates that there are limited studies that have been conducted regarding ways in which teachers guide teaching practice students to develop their own lesson plans for digital media literacy to meet the teaching demands for the millennium generation. One of the expected results or outputs of this research study is a model for teachers to use as an example for training the teaching practice student.

Due to the cultural diversity in South African classrooms the model is designed to be developmentally and culturally appropriate, is geared towards diverse learning styles, and will engage learners whether they attend a school with one computer per learner or a school with no computers at all.

\section{Research Methodology}

\section{Study population}

One teacher from each of the three secondary schools has been selected to participate. This article focuses on teachers from secondary schools in general. The rationale behind dealing with teachers in general and not teachers of a specific discipline is to explore the way teachers in low technology areas can see their development from a digital perspective. It is also assumed that digital education is needed in all fields of education.

\section{Methodology approach}

A qualitative research approach has been used in the study which was conducted at different public schools in the Gauteng region.

\section{Aim}

The main objective of this research study can therefore be defined as follows: To address the practical process of providing a quality digital media literacy programme that is integrated with the school curriculum to challenge the participating teachers to reflect on their own teaching practice to use digital media literacy as an integral part of their pedagogical content knowledge. 
The proposed digital media literacy programme in this study also aims to prepare teaching practice students teachers for the classrooms of the future. Sime and Priestley [19] have noted that teachers often expressed their lack of confidence in their digital technology skills and that this can implicitly affect their attitudes towards the use of digital media literacy in their teaching.

\section{Research design}

The empirical research has been conducted in an interpretive qualitative paradigm underpinned by a complexity theory conceptual framework. In this study, a sample of the teachers' use of digital media literacy lessons is the area of interest. The context is South African secondary schools (see study population above).

The data are gathered over a period of six weeks during the time period of 2013 by means of semi-structured evaluation questionnaires to teachers. Individual interviews and group interviews, and verbalisations were also made use of. This study evaluates the proposed digital media literacy programme's ability to effect improvements in the following objectives for teachers:

- Critical-thinking skills;

- Communicating skills;

- Information-seeking strategies;

- Goal-setting/future aspirations;

- Decision-making/social skills;

- Sharing;

- Exchanging;

- Creating; and

- $\quad$ Digital media literacy.

\section{The main research question}

How do teachers in secondary schools make use of the proposed digital media literacy model for teaching and learning?

Variables of interest for the main research question include the purpose (accessing information, recording, processing information, lesson planning, activities, communicating), type of learning activity, and the type of digital media literacy outcome used.

\section{Sub-research questions}

- What factors impede or encourage the implementation of the digital media literacy model by teachers?

- How do teachers in secondary schools connect and collaborate in their teaching of digital media literacy?

- What is the potential learning and the actual learning that occurs in a teacher's classroom as learners engage in digital media literacy activities?

The variables of interest for these sub-questions include engagement levels, creativity, conceptual understanding, critical thinking, reflection, and connections.

The research questions do not exist in isolation. A logic model (or graphic organiser) (figure 1, adapted from[23]) has guided the data gathering and analysis and the four research questions were embedded in the logic model. They are connected, and through the connections a greater understanding of teaching digital media literacy in the digital age will be constructed.

Constructivist, complexity and connectivist theories underpin the logic model in figure 1.

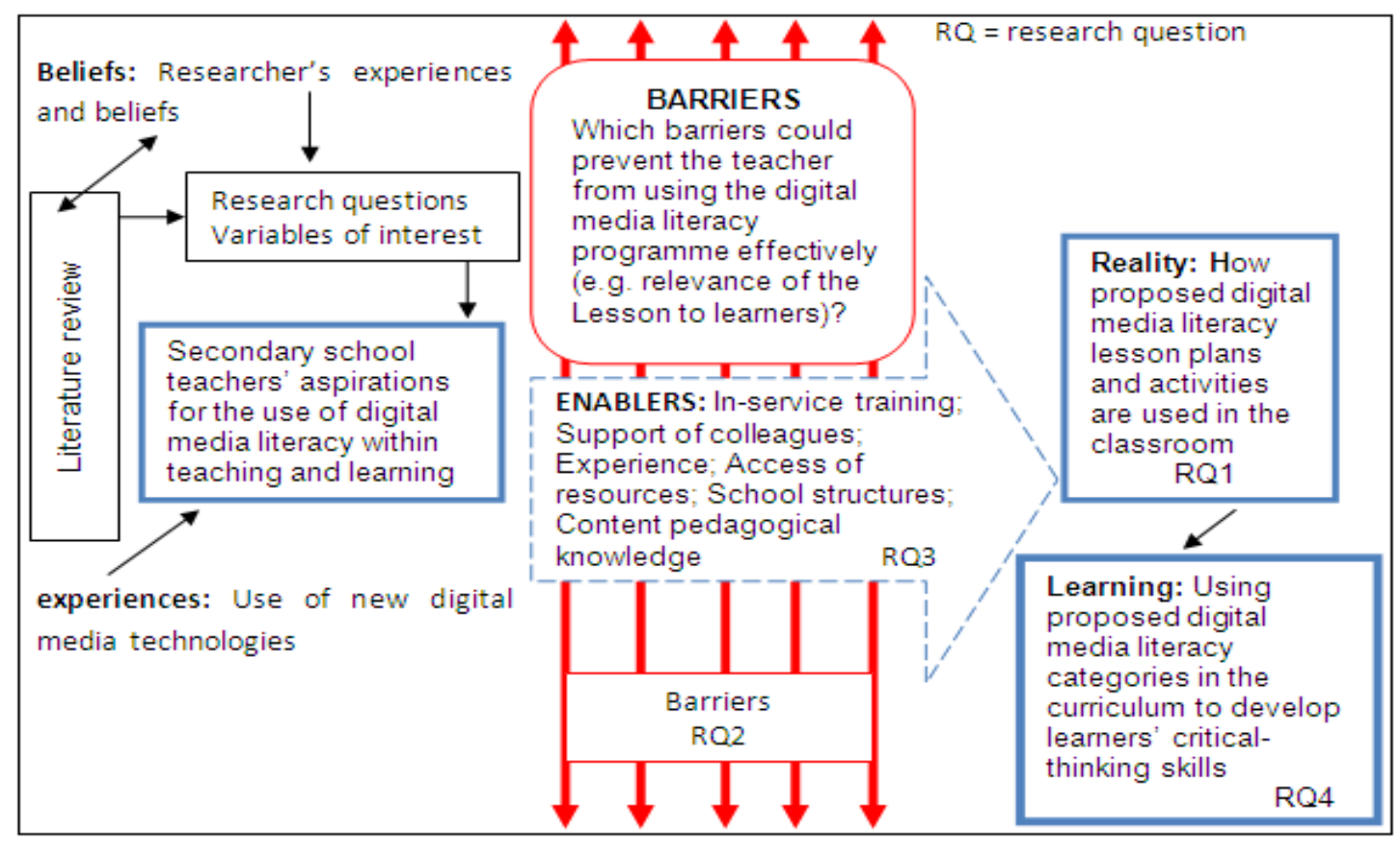

Figure 1. Logic model causal map to guide research(adapted from [23]) 


\section{Constructivist learning theory}

Dewey [15] believes education must engage with and expand experience; those methods used to educate must provide for exploration, thinking and reflection, and that interaction with the environment is necessary for learning. Dewey [15] therefore advocates the learning process of experimental learning through real-life experience to construct and conditionalise knowledge, which is consistent with the constructivist learning theory.

This research looks at the constructivist role of teachers to support learners in becoming effective thinkers. In the constructivist classroom, the teacher's role is to prompt and facilitate discussion. The learning environment should also be designed to support and challenge the learners' thinking. It appears that a focus on learning through practical activity has been categorised as constructivist learning in this research (the work of Hernández-Ramos [16] referred): Through practical activities learners construct meaning on an intrapersonal level, while speech connects this meaning with the interpersonal world shared by the learners and their cultures.

\section{Complexity learning theory}

The literature in this study has been examined from a complexity theory perspective to identify the emerging knowledge of teaching and learning in secondary schools in the digital age - the context in which teachers work. A complex system or organisation consists of a number of levels, with each level having a recognisable open boundary Davis \& Sumara [17]. For example, the complexity of secondary schooling can be examined at a national/regional, school, or classroom level.

A further construct of complexity theory is the decentralised control or bottom-up emergent knowledge Davis \& Sumara [17]. While schools, education systems and classrooms appear to be driven top-down, there is research that reflects how the relationships, history and culture within each level and from the bottom up influence and informally control the changes that occur in a classroom Bishop \& Glynn [20]; Wink [21]. Emerging knowledge within schools is therefore influenced by the parts, participants and processes within the system.

One helpful way to conceptualise complexity theory is in the light of the following example: You cannot make a plant grow. You can, however, provide the necessary ingredients for optimal growth, but even then it may not thrive, for whom knows what the weather, or other random events, will be Morrison [22].

The emerging knowledge within a complex system is informed by its history. In a schooling context this could include how the process of change occurred in the past, or the particular culture or values that developed over time within an organisation. Each school has a unique culture that has developed over time. These constructs are reflected in the underpinning assumptions of schooling and teaching throughout this article. From a complexity theory perspective, each school, region, department and network of teachers has the characteristics of a complex system with unique variables or parts, such as its history, culture, community, leadership, learners, policies, communication networks, structures, resources and considerations for practitioners, policymakers and future researchers, to consider within their context Starkey [23].

\section{Connectivist learning theory}

Connectivism was introduced as a theory of learning based on the premise that knowledge exists in the world rather than in the head of an individual Siemens [24]. Siemens [25] indicates in his paper, A Learning Theory for the Digital Age, the special importance that is given to the effect technology has on how people live, how they communicate, and how they learn.

The effectiveness of learning in a connectivist learning environment would include ideas about knowledge in the digital age, including critical thinking, connections, collaboration, and creating knowledge Siemens [25].

Any measure of effective use of digital media literacy in digital age schooling should be underpinned by a view of knowledge that is relevant to the digital era. Ideas about "knowledge" appear to be changing from something that is found in the heads of individuals or in books to something that is not fixed, is debatable, accessible through a range of mediums, and created through networks, connections and collaboration Gilbert [26]; Siemens [24]. It would therefore be appropriate to include these ideas in a logic model to examine learning through digital media literacy.

Teachers often do not expect learners to be sharing knowledge through connections (a key aspect of learning in the digital age and connectivist learning theory) Siemens [27]. Connectivism's focus on connections requires that learners be exposed to elements that extend beyond the classroom and allow for real-life experience Siemens [27]. In a connectivist environment, a teacher blends his or her educator expertise with learner construction Siemens [24]. The role of the digital media literacy teacher is to create learning resources that expose learners to critical ideas and concepts within the field of digital media literacy. Learners create work which is in full view of peers, and teachers can observe the activities of all learners and draw attention to specific approaches. Learners are at the centre of the learning experience, rather than the teacher and institution Siemens [28].

The researchers are of the opinion that there is a gap between the digital media literacy education currently used in secondary schools and the conceptual understanding of learning and knowledge creation in the digital age. Siemens [28] suggests that education has taken the wrong approach. Education is trying to achieve a task (learning) with a tool (teaching) in an artificial knowledge construct (course). This perspective on teaching and learning then becomes about the institution, not the learner Siemens [28]. This gap between a theoretical education model and the reality in classrooms could be attributable to the time lag between the development of digital media literacy models and their 
subsequent uptake and integration into the complex system of secondary schooling. The teachers in this study were working from a model that is underpinned by connectivist learning theory in the digital age and the proposed digital media literacy programme's pedagogical reasoning and action, which reflects teaching in the digital age that could be useful to secondary schools. Verhagen [29], for instance, has argued that connectivism is not a learning theory, but rather a pedagogical view. Summing up connectivist teaching and learning, Downes [30 p 3] states: "to teach is to model and demonstrate, to learn is to practise and reflect."

After each lesson the teachers completed a self-evaluation form by answering the following questions:

\section{Preparation:}

- How useful was your lesson plan? Were you able to follow it or did you have to depart from it during the lesson?

- What difficulties did you find in planning the lesson?

- Now that you have taught your lesson, what changes would you make to the plan for the next time?

\section{Teaching:}

- How successful was the lesson?

- Which part of the lesson was most successful? Why?

- Which part of the lesson was least successful? Why?

- How did you ensure that all the learners understood and were engaged?

- How much did you use the blackboard, whiteboard or smartboard? Was it effective?

- What other aids did you use? Were they effective?

- What aspect of the lesson gave you the most difficulty? Why?

- How was this lesson different from the one you taught before?

\section{The learners:}

- Which activities did the learners enjoy most? Why?

- What did the learners find the most difficult? Why?

- Did any of the learners fail to participate? If so, why was this?

- What discipline problems were there? What caused them? How did you deal with them?

- What advice might the learners give you about the lesson?

The researchers have used the information in the self-evaluation and skills assessment forms to draw the programme theory evaluation.

\section{Results}

Most teachers enjoy teaching the content they are familiar with and teachers usually view themselves as teaching things which are unknown to learners Shulman [31]. Teachers view themselves as experts in the content knowledge they have acquired. Being knowledge providers is a definition teachers want to relate to in their education world Peterson [4]. Teaching has long been based on a one-way method where teacher knowledge is central in education Tsui [32]. Top-down teaching makes some teachers feel comfortable and safe when they orchestrate the classroom Freeman [33]. With the emergence of digital literacies, teachers' role is changing, and teachers have to be aware of the complex contexts for literacy Leu et al., [7]. Teachers have the challenge of dealing with learners who "are coming to school more literate in the new literacies of ICTs than their teachers" Chandler-Olcott \& Mahar [34 p 361]. Thus, teachers need to rethink their roles in an educational context that is constantly changing with more resources and tools, where learners are familiar with using those tools inside and outside school (Lankshear \& Knobel [35]. Within the frame of digital literacies, teachers are required to be facilitators rather than knowledge providers, while learners are no longer consumers of knowledge Cummins [36].

This study was in effect a "one-shot" study that generated exploratory findings based on a number of extensive reviews of related literature and an analysis of a digital media literacy programme intended for teachers in secondary schools to use as an example for training the teaching practice students. The outcomes of the programme have been compared with what teachers felt they really teach in their classrooms.

The research has revealed that, although teachers may be confident technology users, they often do not have sufficient digital media literacy skills. The participating teachers have used media literacy education in the learning area, but it appeared to be patchy and taught in isolation. Teachers take long to incorporate digital media literacy into their lessons but do not know how. They are unsure how to start, feel overwhelmed, or believe it is more of a hassle than it is worth? The proposed model explores strategies experienced teachers can use to help them turn their digital media literacy into a dynamic, creative teaching tool.

The researchers' conclusion from these results is that digital media literacy education can make a difference in teaching practice training. The study also suggests that digital media literacy education must be a grassroots movement - teachers need to take the initiative in lobbying for its inclusion in the teaching practice training curriculum. All teaching practice students in South Africa could benefit from a digital media literacy programme that enhances their digital media literacy skills and produces teachers capable of succeeding in teaching of the millennium generation.

\section{Barriers and enablers secondary school teachers experienced while attempting to integrate digital technologies into teaching praxis}

The barriers and enablers were based on patterns identified from the empirical study:

- Learners' habits when using media at home are generally unknown to their teachers.

- Leaners' need opportunities to engage with adults in making sense of the wide variety of experiences they 
have with mass media, popular culture, and digital technologies.

- Teachers' own attitudes about digital media literacy education shape their teaching praxis of digital media literacy in the classroom.

- Whether teachers like it or not, this digital media culture is learner's culture. A teacher's job is to prepare them to be able to critically par $\neg$ ticipate as active citizens with the abilities to intelligently and compassionately shape democracy in this new millennium. Digital media literacy programmes offer teachers the framework to build upon their entertainment and social experiences with media so as to pro $\neg$ vide their learners with meaningful academic, civic and public experiences that are critical and empowering.

- A process model for digital and media literacy includes these compo $\neg$ nents: access, analyse, compose, reflect, and take action.

- Digital media literacy class assignments should stimulate more rich conversation about learners' relationship with media and technology. Encourage learners to comment or offer a thought.

- Digital media education is aimed at giving the learner teaching and practice that can deepen his or her understanding of the central role of digital media in our culture. Digital media literacy means more than just understanding of how to use Facebook or conduct an effective Google search - it means being able to use and create digital media to participate in civic life and collaborate around the issues that matter to society. It also means changing the way children think about accessing, analysing, and evaluating media, as the web provides them with an increasing number of choices for information, news, and entertainment and complicates their media landscape with new advertising and marketing tactics

\section{Discussion}

One of the expected results or outputs of this research study is a model for digital media literacy education. The model the researchers propose has a dual purpose: it is 1.) a model for teaching practice students to follow as they are introduced to digital media literacy pedagogical content knowledge as well as the essential skills of inquiry and self-expression necessary for teaching demands for the $21^{\text {st }}$ century and 2.) a model for teachers to use as an example and a source of information for digital media literacy education. The intention is to help teachers develop their own programmes for media literacy that include digital media literacy.

The idea of a dual-purpose model connects with some of the premises of the constructivist paradigm, which considers the learning process as an interactive experience that involves both learner and teacher Hague \& Williamson [37]. In digital media literacy, the constructivist theory provides an interesting background for planning activities, determining attitudes and strategies during the teaching/learning process, and focussing on certain resources. But most of all, it allows the researcher to look at digital media literacy as a learning process for both teaching practice students and teachers, as reflection and collaborative learning are at its core. To integrate all the components of digital media literacy, changes must occur at school level.

Most likely, when teachers think about integrating technology into their curriculum, the technology they thinking of are a computer and the integration involves engaging learners in Web-based lessons and activities. However, many other technology tools besides the computer are available to add interest, knowledge, and skills to their more ordinary lessons. Combined factors can be addressed by adapting the seven outcomes developmental education model to suit a teacher's digital media literacy needs. Each developmental outcome is named according to the general digital media literacy area it addresses. These areas are further broken down into specific areas or topics that need to be addressed in the curriculum. Descriptions of the objectives are suggested.

When the areas of digital media literacy, as shown in table 1 , are examined, the need to address the programme in a holistic manner becomes evident.

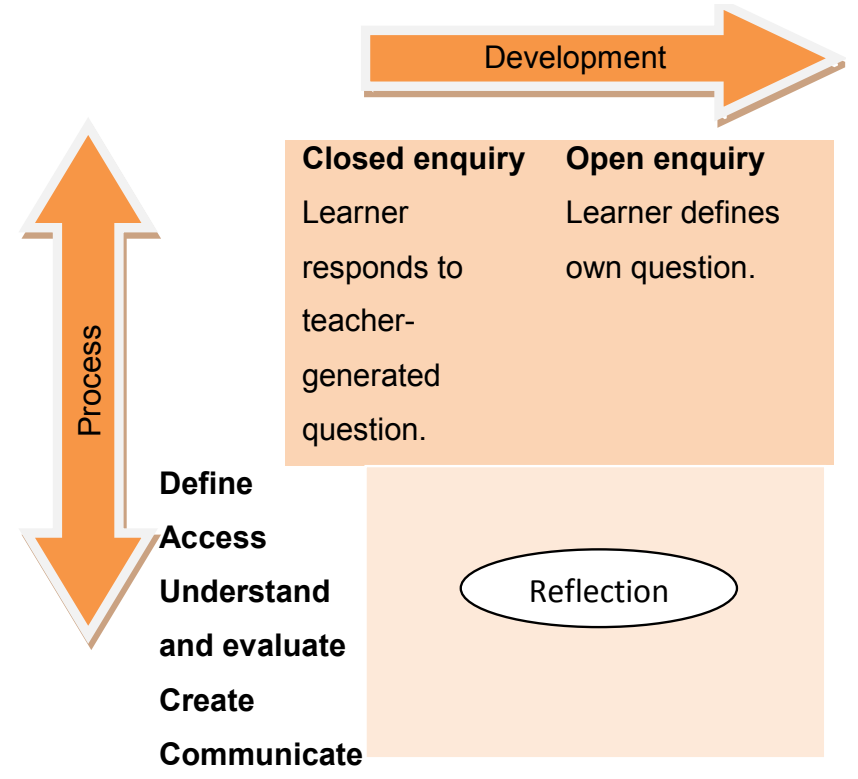

Figure 2. Process to demonstrate digital media literacy 
Table 1. Holistic digital media literacy curriculum development education model

\begin{tabular}{|c|c|c|}
\hline GENERAL AREA & SPECIFIC AREA & DESCRIPTION OF OBJECTIVES \\
\hline 1.Responsibility & $\begin{array}{l}\text { Communicating } \\
\text { information } \\
\text { Range of content }\end{array}$ & $\begin{array}{l}\text { Use content responsibly, ethically and legally with an understanding of ownership issues. } \\
\text { Identify, avoid or challenge content and services that may be unsolicited, offensive or harmful. } \\
\text { Engage with content to become an active and responsible teacher who can exercise his or her } \\
\text { rights to make informed choices and express opinions. } \\
\text { Be aware of computer security and privacy issues and solutions. }\end{array}$ \\
\hline $\begin{array}{l}\text { 2. Communication / } \\
\text { collaboration }\end{array}$ & $\begin{array}{l}\text { Communicating } \\
\text { information }\end{array}$ & $\begin{array}{l}\text { Effectively create content to communicate opinions and ideas through a range of channels. } \\
\text { Develop critical and informed responses to published content. } \\
\text { Recognise what information is needed based on a range of needs, both personal and social. } \\
\text { Create and distribute communications and creative achievements in a range of multimedia } \\
\text { formats. }\end{array}$ \\
\hline 3.Access and selection & $\begin{array}{c}\text { Curriculum } \\
\text { opportunities } \\
\text { Range of content }\end{array}$ & $\begin{array}{l}\text { Choose content appropriately according to the purpose behind the intended use. } \\
\text { Recognise what information is need-based on a range of needs, both personal and social. } \\
\text { Select and evaluate appropriately to make informed choices. } \\
\text { Have the ability to locate and access information needed by determining all possible sources, } \\
\text { selecting the best ones and extracting relevant information. }\end{array}$ \\
\hline 4.Application & $\begin{array}{l}\text { Exploring ideas and } \\
\text { manipulating } \\
\text { information } \\
\text { Capability }\end{array}$ & $\begin{array}{l}\text { Use information in learning, critical thinking, decision making, research and problem solving } \\
\text { in informal and formal education settings. } \\
\text { Process the knowledge and skills to efficiently access, store, organise, retrieve and share } \\
\text { content to meet individual and community needs and interests. } \\
\text { Use a range of practical and conceptual tools of current technology. } \\
\text { Organise information from multiple sources for practical application and integrate it into } \\
\text { existing knowledge. } \\
\text { Have the skills to adapt to using a wide variety of applications. } \\
\text { Have skills in using digital media to reproduce and manipulate data, images, and sound for } \\
\text { creative and practical purposes. }\end{array}$ \\
\hline 5.Evaluation & Evaluation & Review, modify and evaluate work as it progresses. \\
\hline 6.Reflection & Impact of technology & $\begin{array}{l}\text { Use higher order critical-thinking skills to reflect on the nature of information, its conventions, } \\
\text { style and techniques, questioning, analysing and evaluating. } \\
\text { Be aware of bias, misrepresentations, values, and user manipulation through an understanding } \\
\text { of the editorial processes and the motivations, such as commercial or political interests, behind } \\
\text { the content. } \\
\text { Critically reflect on the nature of digital media with an awareness and understanding of its } \\
\text { social and cultural context and impact on individuals and different societies. } \\
\text { Evaluate the benefits, costs, strengths, weaknesses and limitations of digital media } \\
\text { technologies in terms of the individual and society. }\end{array}$ \\
\hline 7.Adaptability & Capability & $\begin{array}{l}\text { Adapt to, understand, evaluate and make use of continually emerging innovations in digital } \\
\text { media technology. }\end{array}$ \\
\hline
\end{tabular}

The model that has been represented in table 1 is developed on the basis of an extensive review of literature on digital media literacy and constitutes an amalgamation of some of the most influential research in this area. As such, the model does not represent a definitive answer to the question of what digital media literacy might be, or provide a template for the development of classroom practices; it offers a conceptual framework for embedding digital media literacy as an aim in the teaching practice training curriculum, and for developing strategies to develop it through classroom activities. It also provides information about what kind of process learners need to go through in order to demonstrate digital media literacy. This process is reflected in figure 2:

The process in figure 2 is based on the notion that learners investigate questions and problems set by teachers, and that, over time, they should develop sufficient confidence and competence in their skills, knowledge and understanding of digital media literacy to be able to define their own questions for enquiry. The model therefore offers a potentially useful structure for classroom activities that are aimed at fostering critical thinking.
The process the model suggests is not necessarily linear and may involve moving up and down the stages as learners refine their tasks and their thinking.

The proposed model suggests that digital media literacy is an amalgamation of:

- knowledge of digital tools: hardware/software and competence;

- critical skills:evaluation and contextualisation;

- social awareness: understanding your identity; collaborating and communicating to audiences in context.

\section{Conclusions}

The researchers believe that a successful combination of these areas is the key to translating digital media literacy into teaching practice in order to contribute to the development of teaching practice students' informed digital participation. 


\section{REFERENCES}

[1] Okeke, O., van Wyk, M., \& Phasha, N. Schooling, society and inclusive education. Goodwood: Oxford University Press; 2014.

[2] Marais. P., \& Meier, C. Hear our voices: student teacher's experience during practical teaching. Africa Education Review; 2004; 1:220-233.

[3] Louw, L.P., \& du Toit, E. R. Help I'm a student teacher! Pretoria: Van Schaik Publishers; 2010.

[4] Peterson, S.L. Teachers and Technology: Understanding the teachers' perspectives of technology. San Francisco: International Scholars Publications; 1999.

[5] Codrington, G., \& Grant-Marshall, S. Mind the gap. Cape Town: Penguin Books; 2012.

[6] Williams, D. A., \& Wavell, C. Secondary school teacher conceptions of student information literacy. Journal of Librarianship and Information Science. 2007; 39:199-212.

[7] Leu, Jr., D.J., Kinzer , C.K., Coiro, J., \& Cammack, D.W. Toward a theory of new teracies emerging from the Internet and other Information and Communication Technologies. In R.B. Ruddell, \& N.J. Unrau (Eds.). Theoretical Models and Processes of Reading. Newark, DE: International Reading Association; 2004. p. 1570-1613.

[8] Newman, T. Consequences of a digital literacy review: moving from terminology to action. 2009 [cited 2010 September 11] Available from http://www.slideshare.net/Ta bet

haNewman/digital-literature-review-from-terminology-to-act ion

[9] Almas, A. G., \& Krumsvik, R. Digital literate teachers in leading edge schools in Norway. Journal of in-Service Education. 2007; 33(4):479-497.

[10] Levine, A., \& Cureton, J. S. When hope and fear collide: A portrait of today's college student. San Francisco: Jossey Bass; 1998

[11] Rosen, L. Rewired: Understanding the iGeneration and the Way They Learn. New York: Palgrave Macmillan; 2010.

[12] Hobbs, R., \& Frost, R. Instructional practices in media literacy education and their impact on students' learning: A look at media literacy in practice in one American high school. 2001 [cited 2011 February 4] Available from http://www.medialit.org/reading-room/instructional-practice s-media-iteracyeducation-and-their-impact-students-learning.

[13] Ungar, M. We generation: Raising socially responsible kids. Toronto: McClelland \& Stewart; 2009.

[14] Pungente, S. J. Nine factors that make media literacy flourish. 2010 [cited 2011 March 6] Avialable from http://www.media-awareness.ca/english/resources/education al/ teaching_backgrounders

[15] Dewey, J. Thinking in education. 2009 [cited 2011 August 12] Available fromhttp://www.ilt.columbia.edu/publications/Pro jects/digitexts/dewey/d_e/chapter12.html

[16] Hernández-Ramos, P. If not here, where? Understanding teachers' use of technology in Silicon Valley schools. Journal of Research on Technology in Education. 2005; 38(1):39.

[17] Davis, B., \& Sumara, D. J. Complexity and education: Inquiries into learning, teaching and research. Mahwah, NJ: Lawrence Erlbaum Associates; 2006.

[18] Ngidi, D.P., \& Sibaya, P.T. Student teacher anxieties related to practice teaching. South African Journal of Education. 2003; 23:18-22.

[19] Sime, D., \& Priestley, M. Student teachers' first reflections on information and communications technology and classroom learning: implications for initial teacher education. Journal of Computer Assisted Learning. 2005; 21(2):130-142.

[20] Bishop, R., \& Glynn, T. Culture counts: Changing power relations in education. Palmerton North: Dunmore Press; 1999.

[21] Wink, J. Critical pedagogy: Notes from the real world. Boston: Allyn \& Bacon; 2000.

[22] Morrison, K. School leadership and complexity theory. London \& New York: Routledge Falmer; 2002.

[23] Starkey, L. Digital saviors: Digitally able secondary school teachers in their first year of teaching. 2010 Thesis. Wellington: Victoria University of Wellington. [cited 2011 November 21] Available from researcharchive.vuw.ac.nz/bit stream/handle/10063/1 0063/1176/thesis/pdf?...1

[24] Siemens, G. Knowing knowledge. 2006 [cited 2011 November 10] Available from http://ltc.umanitoba.ca/Knowi ngKnowledge/index.php/Main_Page

[25] Siemens, G. University of Manitoba 2008 online connectivism conference. 2008 [cited 2008 November, 2008 14] Available from http://docs.google.com/View?docid=anw 8wkk6fjc_14gpb qc2dt

[26] Gilbert, J. Catching the knowledge wave? The knowledge society and the future of education. Wellington: NZCER Press; 2005.

[27] Siemens, G. Special Issue -- Connectivism: Design and Delivery of Social Networked Learning. International Review of Research in Open and Distance Learning. 2011; 2(3):1-5.

[28] Siemens, G. Connectivism: A learning theory for the digital age. 2004 [2011 March 16] Available from http://www.elearnspace.org/Articles/connectivism.htm

[29] Verhagen, P. Connectivism: a new learning theory? 2006 [cited 2011 November 18] Available from https://www.surfspace.nl/nl/Redactieomgeving/Publicaties/D ocuments/ Connectivism\%20a\%20new\%20theory.pdf

[30] Downes, S. "What Connectivism Is." 2007 [cited 2013 May 03] Available from http://www.downes.ca/me/articles.htm

[31] Shulman, L.S. Knowledge and teaching: Foundations of the new reform. Harvard Educational Review. 1987; 57:1-22.

[32] Tsui, A. B. M. Teacher education and teacher development. In E. Hinkel (Ed.). Handbook of Research in Second Language Teaching and Learning. Hoboken: Routledge; 2009. p. 21-40.

[33] Freeman, D. (1989). Teacher training, development, and decision making: A model of teaching and related strategies 
for language teacher education. TESOL Quarterly. 1989; 23(1):27-45.

[34] Chandler-Olcott, K., \& Mahar, D. 'Tech-savviness' meets multiliteracies: Exploring adolescent girls' technology-related literacy practices. Reading Research Quarterly. 2003; 38:356-385.

[35] Lankshear, C., \& Knobel, M. New Literacies: Everyday Practices and Classroom Learning, 3rd ed. London: Open
University Press; 2011.

[36] Cummins, J., Brown, K., \& Sayers, D. Literacy, Technology, and Diversity: Teaching for Success in Changing Times. Boston: Allyn \& Bacon/Pearson; 2007.

[37] Hague, C., \& Williamson, B. Digital participation, digital literacy, and school subjects. 2009 [cited 2011 May 20] Available from https://www.evernote.com/shard/s18/note/de e57c96.../education 